\title{
OS INSPETORES DE ALUNOS DO COLÉGIO PEDRO II EM SEUS PRIMEIROS ANOS DE FUNCIONAMENTO (1837-1857)
}

\author{
Letícia Sousa Campos da Silva* \\ https://orcid.org/0000-0001-5319-6033
}

\section{RESUMO}

Para muitos autores, a criação do Colégio Pedro II (CPII) foi uma experiência inovadora no século XIX. Na historiografia acerca desta instituição despontam duas tendências: a ênfase em seus alunos e professores, como se tivessem sido os únicos sujeitos no interior da escola, e a utilização de um determinado documento - a Memória Histórica do Colégio de Pedro II (MHCPII) - sem realizar uma crítica de seu conteúdo. Neste artigo abordo a possibilidade de investigar a situação dos inspetores de alunos do CPII entre 1837, data de criação do colégio, e 1857, ano no qual foi dividido em dois estabelecimentos de ensino. Após apresentar breve panorama sobre os estudos a respeito da escola, analiso o modo como esses trabalhadores são representados na MHCPII e, em seguida, confronto estas informações com os dados extraídos de outras fontes, tais como os dispositivos legais, o Almanak Laemmert e o material trocado entre os reitores do CPII e os representantes do Império. Concluo demonstrando omissões na MHCPII sobre as condições laborais dos inspetores e as tensões delas decorrentes.

Palavras-chave: Colégio Pedro II. Memória Histórica do Colégio Pedro II. Inspetores de alunos.

\section{ABSTRACT}

\section{THE STUDENT INSPECTORS OF COLÉGIO PEDRO II IN ITS EARLY YEARS (1837-1857)}

For many authors, the creation of Colégio Pedro II (CPII) was an innovative experience in the $19^{\text {th }}$ century. Two trends emerge in the historiography of this institution: the emphasis on its students and teachers, as if they had been the only subjects inside the college; and the use of a document - the Historical Memory of the College of Pedro II (Memória Histórica do Colégio de Pedro II - MHCPII) - without critical content review. In this article, I discuss the possibility of investigating the situation of CPII student inspectors between 1837, the date of foundation of the school, and 1857, the year in which it was divided into two educational establishments. After presenting a brief overview

* Doutoranda em História pela Universidade Federal Fluminense (UFF). Bolsista CNPQ. Professora do Colégio Pedro II. E-mail: silvaleticiasc@gmail.com. 
of studies about the school, I analyze how these professionals are represented at MHCPII. Subsequently, I compare this information with data extracted from other sources, such as legal provisions, the Almanak Laemmert, and material exchanged between rectors of CPII and representatives of the Empire. I conclude by showing omissions in the MHCPII on the working conditions of inspectors, and the tensions arising therefrom.

Keywords: Colégio Pedro II. Historical Memory of Colégio Pedro II. Student inspectors.

\section{RESUMEN}

\section{LOS INSPECTORES ESTUDIANTILES EN LOS PRIMEROS AÑOS DE FUNCIONAMIENTO DEL COLEGIO PEDRO II (1837-1857)}

Para muchos autores, la creación del Colegio Pedro II (CPII) fue una experiencia innovadora en el siglo XIX. En la historiografía sobre esta institución, surgen dos tendencias: el énfasis en sus estudiantes y docentes, como si hubieran sido las únicas personas dentro del colegio; y el uso de un documento - la Memoria Histórica del Colegio de Pedro II (MHCPII) - sin una evaluación crítica de su contenido. En este artículo, analizo la posibilidad de investigar la situación de los inspectores estudiantiles de CPII entre 1837, la fecha de creación del colegio, y 1857, año en que se dividió en dos establecimientos educativos. Después de presentar una breve descripción de los estudios sobre el colegio, analizo cómo están representados estos trabajadores en MHCPII. A continuación, comparo esta información con datos extraídos de otras fuentes, como disposiciones legales, el Almanak Laemmert, y material intercambiado entre rectores del CPII y representantes del Imperio. Concluyo mostrando omisiones en el MHCPII sobre las condiciones de trabajo de los inspectores y las tensiones derivadas.

Palabras clave: Colegio Pedro II. Memoria histórica del Colegio Pedro II. Inspectores estudiantiles.

Para muitos autores, a criação do Colégio Pedro II (CPII) foi uma experiência inovadora no século XIX. ${ }^{1}$ No Dicionário do Brasil Imperial,

1 Ao longo de sua história, essa instituição recebeu nomes diferentes. Fundado como Seminário dos Órfãos de São Pedro, em 1739, no decorrer do tempo se tornou o Seminário de São Joaquim, em 1766, o Real Colégio de São Joaquim, em 1813, e o Seminário Imperial de São Joaquim, em 1824, até ser transformado no Imperial Collegio de Pedro II, em 1837, que previa a admissão de alunos em regime de internato ou externato. Em 1857, porém, esses regimes foram separados em dois estabelecimentos distintos - o externato permaneceria na Corte enquanto o internato se instalaria no Engenho Velho -, mantendo-se o único nome para a escola. Com a Proclamação da República, o colégio foi convertido no Instituto Nacional de Instrução Secundária até o ano seguinte, quando teve seu nome alterado para Gymnasio Nacional. Em 1892 houve a extinção do internato e sua substituição em um segundo externato. Já em 1909 o primeiro externato tornou-se o Externato Nacional Pedro II e o segundo, o Internato Nacional Bernardo de Vasconcelos. Apenas em 1911 seria adotada a denominação de Collegio
Lúcia Neves declarou que, ao ser instituído em 1837, converteu-se "no único colégio de instrução secundária oficial do país" e "as instituições particulares de ensino secundário passaram a seguir os currículos e livros ali utilizados" (NEVES, 2008, p. 147-148). Fernando Penna alcançou percepção semelhante ao anunciar que, embora não tenha sido o primeiro estabelecimento a receber o nome de colégio no Brasil, o CPII

[...] constituiu uma mudança profunda no nível de instrução que viria a ser chamado secundário (Penna, 2008). Afirmo que 'viria a ser chamado', porque constatei que, nos seus relatórios anuais apresentados à Assembleia Geral Legislativa,

Pedro II (DÓRIA, 1997). Embora neste texto o foco seja o período imperial, adotei o corrente nome da escola. 
aqueles que então ocupavam o cargo de ministro do Império, não falavam em 'instrução secundária' antes do ano da criação do Colégio de Pedro II (1837), mas em 'estudos (ou aulas) menores'. (PENNA, 2009, p. 39-40, grifo do autor).

Esse autor esclareceu que nos documentos anteriores à fundação da escola que abordavam a instrução pública apareciam os termos "estudos maiores" e "estudos menores". Enquanto o primeiro abrangia as academias do império, o que mais tarde se tornou o ensino superior, o segundo era oferecido por meio das aulas públicas nas escolas de primeiras letras ou nas cadeiras avulsas, possuindo um caráter preparatório para o ingresso nas academias. De acordo com Penna (2009), a proposta do CPII configurou um rompimento desse acordo social não somente por ter instaurado o "currículo colegial" - expressão que encontrou em fontes da época - em substituição às cadeiras avulsas, mas também por ter estabelecido o título de Bacharel em Letras a seus egressos e com ele o acesso direto às universidades - o que entendeu como uma "capa do imperador" sobre a escola que lhe forneceu proteção e legitimidade.

Já para Carlos da Cunha Júnior (2008), a singularidade do estabelecimento de ensino foi o papel relevante que assumiu no projeto de expansão e reprodução dos Saquaremas - políticos fluminenses que representavam o grupo dominante no seio do Partido Conservador, o qual assumiu o controle do Estado Imperial nos últimos anos das Regências.

Os Saquaremas buscaram imprimir a direção da construção do Estado e do Império do Brasil. Visavam assegurar a continuidade da ordem, ou seja, do caráter elitista e desigual da sociedade brasileira, através da manutenção do monopólio da mão-de-obra, da terra, dos negócios, da política e dos homens imperiais. Nesse processo de difundir e assegurar a adesão à ordem e aos princípios conservadores, educação e instrução tornaram-se preocupações dos dirigentes saquaremas. Seus olhos estavam postos sobre todos, tanto sobre o homem comum, quanto sobre o grupo do qual faziam parte, a boa sociedade imperial. Ao promover sua intervenção no Es- tado, em busca de ditar os rumos da construção da Nação Brasileira, os Saquaremas construíam a si próprios e preparavam sua expansão. (Mattos, op. cit.) Em nossa visão, este processo de expansão Saquarema ajuda a explicar a criação do Colégio Pedro II. (CUNHA JUNIOR, 2008, p. 23 , grifo do autor).

As interpretações brevemente expostas exemplificam as principais abordagens sobre a escola. Se, por um lado, pesquisadores têm tomado o CPII como objeto de análise para identificar as dinâmicas de seu desenvolvimento curricular voltando-se, sobretudo, para os processos de estruturação das disciplinas escolares no país, ${ }^{2}$ por outro, alguns têm investigado as associações entre as suas propostas pedagógicas e os projetos do Estado. ${ }^{3}$ Em que pesem algumas diferenças de concepção e escopo, em meio a esses trabalhos discerni duas tendências: a ênfase em seus docentes e discentes, como se tivessem sido os únicos sujeitos a interagirem no interior da escola, e a utilização de um determinado registro histórico sobre o CPII, sem que se realize uma crítica de seu conteúdo.

Quanto ao primeiro ponto, apresento alguns casos de pesquisas sobre o século XIX, se bem que igualmente tenha identificado esta postura em estudos acerca do CPII em outros momentos. ${ }^{4}$ Cito inicialmente o livro de Arlete Gasparello (2002) por representar um marco na história do Ensino de História. Embora não correspondesse a seu objetivo principal de analisar os compêndios desta disciplina adotados pelo CPII no intervalo de 1838 a 1920 e mapear os conceitos de nação exprimidos nestes materiais, essa autora voltou seu olhar para a dinâmica de professores e alunos da escola, concluindo que eles, juntamente com a estrutura curricular livresca que tinha sido

2 Ver Rocha (1996, 2014), Razzini (2000), Gasparello (2002), Tavares (2002), Ferreira (2005), Soares (2009), Santos (2011), Finocchio (2013) e Jornada (2013).

3 Ver Massunaga (1989), Andrade (1999), Cunha Júnior (2008), Polon (2004), Alves (2006), Hauer (2007), Moisés (2007), Nunes (2007), Marques (2011), Patroclo (2014) e Carlos Souza (2010, 2015).

4 Ver Santos (2011) e Marques (2011). 
adotada, denotavam um projeto de sociedade brasileira civilizada no estilo europeu. Já José Finocchio (2013), que elegeu como propósito a compreensão do processo de inserção da Ginástica no colégio entre 1839 e 1889, utilizando como fontes os relatórios ministeriais, o Almanak Laemmert (LAEMMERT; LAEMMERT, 2020) e a legislação educacional da época, consagrou parte de sua tese para catalogar a ocupação futura dos formandos entre $1850 \mathrm{e}$ 1869 e para recapitular o percurso de diversos mestres. José Jornada (2013), que tratou do ensino de Química no mesmo período através do exame das reformas de ensino ocorridas naquele tempo e dos programas da disciplina empregados pelo colégio, também explorou seu alunado, o que o levou à conclusão de que seu perfil e visão de mundo foram determinantes para a definição da Química difundida pela escola.

Carlos Souza (2015), por sua vez, ao comparar o CPII, o Ginásio Baiano ${ }^{5}$ e o Culto à Ciência ${ }^{6}$ por serem três instituições de ensino secundário classificadas como modelares durante o Segundo Reinado, para observar os diferentes projetos educacionais vinculados a parcelas distintas das elites imperiais, efetuou um exame levando em consideração três dimensões: a origem da escola, seu currículo escolar e os perfis de docentes considerados representativos. Nas palavras desse autor,

[...] o interesse principal, ao final, é [...] sugerir, por meio da apresentação da trajetória de personagens exemplares - diretores, professores e alguns alunos egressos dessas instituições - os vínculos entre projetos educacionais e ação política no contexto de crise política do Império. (SOUZA, C., 2015, p. 8).

5 Inaugurado em Salvador no ano de 1858, o Ginásio Baiano teve suas atividades encerradas em 1870 quando seu criador, Abílio Cesar Borges, mudou para o Rio de Janeiro. Nesta cidade Borges estabeleceu, no ano seguinte, o Colégio Abílio.

6 Instituído na cidade de Campinas em 1874, pela sociedade homônima que mantinha relações com a maçonaria e as propostas republicanas, o Culto à Ciência funcionou até 1890. Tendo sido tombado como patrimônio cultural nos anos 1980, hoje encontra-se em funcionamento integrando a rede estadual de São Paulo.
Sendo assim, em sua tese encontram-se quadros sumarizando dados a respeito dos professores do CPII nomeados em 1838 e dos bacharéis formados por esta instituição entre 1843 e 1888, além das ênfases dadas a alguns docentes.

Entre os trabalhos encontrados, o que mais pareceu avançar em romper a visão limitada sobre as pessoas existentes na escola foi o do já mencionado Carlos da Cunha Júnior (2008): um livro no qual pretendeu testar a hipótese de que o CPII difundiu um projeto pedagógico para a formação dos jovens da elite imperial brasileira de hegemonia saquarema, desde sua fundação até os anos finais do Império. Na introdução do texto ele afirmou a intenção de focalizar os vários atores envolvidos na proposta educativa do colégio e, por isso, dedicou um capítulo aos estudantes e outro a seus "agentes escolares profissionais". De bastante proveito foi o fato de ter abarcado nesse segundo capítulo os inspetores de alunos ao lado dos primeiros reitores, vice-reitores e professores. Contudo é preciso pontuar que esse autor separou tão somente 2,5 páginas para se ocupar dos inspetores, em comparação com as 11 laudas que destinou aos professores, o que acarretou comentários superficiais acerca da situação daqueles. Não obstante esta irresoluta inclusão, o capítulo escrito por Cunha Junior (2008) passou longe de produzir conhecimento acerca dos "agentes escolares profissionais" porque, assim como outros autores, omitiu vários indivíduos de cuja atuação o funcionamento do colégio também dependeu.

Percebendo, então, essa lacuna na historiografia sobre o CPII, tenho procurado aproximar os campos da História das Instituições Escolares e da História do Trabalho. Em minha pesquisa, ainda em andamento, sobre o conjunto de trabalhadores dessa escola ao longo do império, já descobri uma diversidade de cargos e/ou funções na escola, tais como apontador das aulas, bedel das aulas, bibliotecário/guarda da biblioteca, capelão, chefe da vestiaria, coadjuvante dos professores de desenho e música, 
comprador, contínuo da tesouraria, cozinheiro/mestre de cozinha, criado, despenseiro, encarregado da conservação dos gabinetes de ciências naturais/preparador das matérias do ensino de ciências naturais, encarregado do correio, escriturário da tesouraria, escrivão, explicador, fiel do armazém, guarda do pátio interior, inspetor de alunos, inspetor da enfermaria, inspetor da rouparia/da vestiaria, médico, porteiro, professor, rabequista auxiliar do professor de dança, "refeitoreiro", reitor, repetidor, sacristão, secretário, substituto, tesoureiro, tocador de sino e vice-reitor.

Uma vez que nesse processo de coleta de dados consegui levantar informações significativas sobre os inspetores de alunos, resolvi abordá-las neste texto tomando como marco temporal - e isso é o que denominei primeiros anos de atividade da instituição - o intervalo entre 1837, data de sua criação, e 1857, ano no qual foi dividida em dois estabelecimentos: 0 externato, que permaneceria no prédio em que o colégio se encontrava na Corte, e o internato, que foi instalado em um edifício fora da cidade, no Engenho Velho. ${ }^{7}$ A justificativa para restringir o estudo a este período é a possibilidade de a cisão em duas unidades ter suscitado novas dinâmicas laborais, aspecto cuja verificação está em desenvolvimento.

Se até aqui busquei tornar compreensível a relevância deste artigo e elucidar seus eixos temático e cronológico, a fim de explicar meu procedimento de análise é necessário comentar a segunda tendência dos trabalhos acerca do CPII: o recorrente uso da Memória Histórica do Colégio de Pedro II (MHCPII) (DÓRIA, 1997) sem aferir sua validade. Em virtude de ter estruturado um farto repertório de informes a respeito da escola, a obra - redigida por Escragnolle Dória (1869-1948) ${ }^{8}$ e publicada em 1937 para celebrar seu primeiro centenário

7 Decreto $\mathrm{n}^{\mathbf{0}} 2006$, de 24 de outubro de 1857 (BRASIL, 1857).

8 Nascido no Rio de Janeiro filho de um general reformado e tendo como tios pelo lado materno o Barão de Itaipu (18291909) e o Visconde de Taunay (1843-1899), Luís Gastão d'Escragnolle Dória foi um professor do CPII entre 1906 e 1937, e também arquivista, redator de alguns periódicos e tradutor de diversas obras.
- tem servido de fundamento para a maioria dos estudos. Consoante Sátiro Nunes (2007), apesar de seu "caráter apologético, ou epidítico", demonstrado nas tentativas de retratar um passado glorioso da instituição com a minimização dos desgastes em sua trajetória, ela tornou-se "o alicerce material da memória construída do Colégio de Pedro II e como história oficial autorizada, a base de todas as representações acerca da instituição." (NUNES, 2007, p. 135-136).

Tanto é assim que destaco duas ocorrências do discurso de promoção da MHCPII propagadas pela Comissão de Atualização da Memória Histórica do CPII (CAMHCPII). ${ }^{9}$ No prefácio da versão reimpressa do texto de Dória com atualização da ortografia editada em $1997^{10}$ foi enunciado o seguinte: "A Memória Histórica é parada obrigatória para qualquer estudioso que pretenda penetrar no universo cultural brasileiro, quer na política, quer nas artes, quer na ciência, quer na Educação." (DÓRIA, 1997, p. xii). Alguns anos mais tarde, no primeiro livro promovido pela comissão no século XXI, em uma tentativa de dar continuidade à empreitada do professor Dória, ${ }^{11}$ afirmou-se:

Aos que querem conhecer, trabalhar e pesquisar sobre os cem primeiros anos - 1837 a 1937 - têm que se fundamentar em Eugênio Raja Gabaglia e Escragnolle Dória, colhendo dados e fatos históricos tão somente descritivos. Eles evitaram tecer considerações crítico explicativas, não obstante possuírem elevados méritos e larga capacidade profissional. (COLÉGIO PEDRO II, 2013, p. 13)

9 Constituída pela Portaria no 600, de 01 de outubro de 1990, a CAMHCPII tem como um de seus objetivos resgatar, organizar e divulgar o acervo manuscrito, iconográfico, bibliográfico e documental da história e memória do CPII, continuando o trabalho do professor Dória (COLÉGIO PEDRO II, 2014).

10 Tal edição foi lançada por meio de uma parceria entre o CPII e o Instituto Nacional de Estudos e Pesquisas Educacionais (INEP) na comemoração dos 160 anos do colégio, e os 60 anos do Instituto. Ver: DÓRIA, 1997.

11 Além da obra em destaque, divulgada em 2013, tal comissão organizou ainda um livro em 2018 no qual se reproduz o discurso favorável à MHCPII: “[...] a obra seminal do Professor Luiz Gastão d'Escragnolle Doria é [...] fonte obrigatória para todo pesquisador que se propõe a investigar os primeiros cem anos do Colégio Pedro II" (COLÉGIO PEDRO II, 2018, p. 11). 
No trecho é perceptível o elogio que se estendeu à Raja Gabaglia (1862-1919), o qual Escragnolle Dória consultou para elaborar seus escritos. ${ }^{12}$ Nele também ficou evidente o ingênuo ponto de vista que presume a possibilidade de neutralidade e descarta a noção de intencionalidade por detrás das escolhas dos pesquisadores. Embora nenhum dos especialistas sobre o CPII elencados acima tenha externalizado concordância com esta perspectiva, na prática, a maioria deles lançou mão das observações do professor catedrático como se fossem imparciais. Jornada (2013), por exemplo, imputou à MHCPII o status de fonte primária, colocando-a no mesmo nível que o primeiro regulamento do colégio. Já Finocchio (2013) argumentou que ela é um memorial de elevado valor histórico por resgatar o cotidiano da escola. E Carlos Souza (2015, p. 68) ratificou esta ideia afirmando que "questões cotidianas da instituição são encontradas com maior dificuldade dentre a vastidão de documentos, e é aí que a obra de Dória vem suprir a lacuna". Estas assertivas prenunciaram um procedimento concretizado ao longo desses trabalhos: o vício de não colocar à prova aquilo que se leu no compêndio de Dória e, ao invés disso, embasar-se seguramente em seus relatos.

Penna (2008) foi o único que sinalizou a necessidade de avaliação do teor dos dados disponíveis na MHCPII. Em determinada parte de seu texto, asseverou:

Os textos de Dória e Gabaglia, os dois principais memorialistas a escrever sobre o CPS, vem [sic] sendo monumentalizados enquanto as fontes inquestionáveis sobre o que aconteceu no colégio. Mas, como tivemos acesso às fontes primárias, sempre questionei as suas versões através dos indícios encontrados nas fontes. (PENNA, 2008, p. 48).

12 Trata-se do primeiro anuário do CPII, organizado em 1914 por Eugênio de Barros Raja Gabaglia. Seguindo os passos do pai, que foi professor da Academia de Marinha, Gabaglia participou de algumas comissões técnicas pelo Ministério da Marinha, ocupando cargos de certo destaque. Foi professor da Escola Naval, da Escola Naval de Guerra e do CPII, do qual foi diretor entre 1912 e 1914 (DASSIE; SOARES, 2010).
Foi justamente esse cruzamento de versões que me empenhei a realizar no tocante aos inspetores de alunos do CPII nas duas décadas iniciais de atividade da escola. Deste modo, na próxima seção analisarei o que se disse sobre eles na MHCPII e, na outra parte, compararei com o modo como figuraram em outras fontes.

\section{Os inspetores de alunos na MHCPII}

No introito da MHCPII, assumindo a dificuldade de efetuar uma história completa da escola - afinal, seria "matéria para não poucos volumes, resultantes de pesquisas exaustivas, algumas infrutíferas" - Dória comunicou, ao contrário disso, o desígnio de elaborar uma memória histórica que, não sendo um "quadro acabado, sim esboço em leve tinta", configurasse um "resumo do essencial na história da primeira centúria do Colégio de Pedro Segundo" mediante a apresentação de "testemunhos fidedignos da vida da instituição" (DÓRIA, 1997, p. 13). A questão é que, em sua mea-culpa retórica, ele acabou expressando um pressuposto da construção de narrativas históricas: "o que é definido oficialmente como 'passado' é e deve ser claramente uma seleção particular da infinidade daquilo que é lembrado ou capaz de ser lembrado" (HOBSBAWM, 1998, p. 22, grifo do autor). E admitir que seleções ocorrem é considerar que, em meio a um movimento de lembrança, promovem-se esquecimentos, algo que é dependente das circunstâncias socioeconômicas, políticas, culturais. Deriva daí a indagação elementar que formulei para escrever este artigo: o que o memorialista lembrou e esqueceu sobre os inspetores de alunos do CPII?

Antes de responder a essa pergunta, creio ser útil expor alguns apontamentos mais gerais sobre a obra. 0 primeiro deles é o de que Escragnolle Dória não explicitou na introdução nem no decorrer do exemplar quais critérios foram utilizados para estruturá-lo. Para se ter uma ideia, a MHCPII está segmentada em quin- 
ze seções, mas não ficou evidente o raciocínio do autor sequer em relação a esta divisão. A despeito de inexistir uma discussão teóricometodológica que justifique as intenções de sua redação, identifiquei a importância que deu às origens, uma vez que dedicou 12 páginas para recontar fatos acerca dos precedentes do CPII, e 18 para noticiar os acontecimentos dos dois primeiros anos de funcionamento do colégio. Quanto aos demais capítulos, não pareceu mesmo haver um padrão, como é possível verificar no Quadro 1.

Quadro 1 - Relação de capítulos, intervalo ou assunto, e número de páginas da MHCPII

\begin{tabular}{|c|c|c|}
\hline Capítulo & Intervalo ou assunto & Número de páginas \\
\hline I & A instrução secundária anterior à fundação do Colégio & 12 \\
\hline II & $1838-1839$ & 18 \\
\hline III & $1840-1843$ & 16 \\
\hline IV & $1844-1851$ & 7 \\
\hline V & $1851-1855$ & 12 \\
\hline VI & $1855-1858$ & 12 \\
\hline VII & $1859-1865$ & 13 \\
\hline VIII & $1866-1875$ & 21 \\
\hline IX & $1876-1881$ & 26 \\
\hline X & $1882-1889$ & 22 \\
\hline XI & $1890-1917$ & 21 \\
\hline XII & $1917-1925$ & 24 \\
\hline XIII & $1925-1931$ & 12 \\
\hline XIV & $1932-1937$ & 72 \\
\hline XV & O Instituto dos Bacharéis em Letras & 21 \\
\hline
\end{tabular}

Fonte: Elaborado pela autora deste artigo com base em Dória (1997).

* Em conformidade com Dória, essa agremiação, formada pelos egressos do CPII, foi criada em 1863 (DÓRIA, 1997).

Em segundo lugar, devo reconhecer que a MHCPII se amparou em diversas fontes primárias, tais como o discurso de inauguração proferido pelo ministro Bernardo de Vasconcellos; estatutos e regulamentos da escola; e ofícios, portarias e avisos trocados entre os reitores do CPII e os responsáveis pela instrução pública. Em determinados momentos, Dória (1997) chegou a reproduzi-las na íntegra, o que deixou o texto prolixo. Muitas vezes, porém, não esclareceu com precisão o documento a que estava se referindo, embora com frequência tenha utilizado aspas para indicar frases que não eram de sua autoria. No entanto, o aproveitamento dessas fontes foi bastante seletivo, uma vez que uma terceira anotação importante sobre o livro é o fato de relatar os pormenores de diversos professores da casa sem demonstrar um esforço equivalente para enfatizar as biografias de outros trabalhadores, com exceção de reitores e vice-reitores. É pertinente notificar que oito dirigentes da escola exerceram simultaneamente o magistério no colégio e, por isso, salientar seus históricos é também valorizar os docentes do CPII.

Nesse contexto, não causou admiração perceber que ocorreram escassas menções aos inspetores de alunos ao longo de toda a MHCPII. Especificamente no que concerne aos seis primeiros capítulos que cobrem o eixo cronológico adotado neste artigo, houve, na verdade, apenas três tipos de referências. Uma delas diz respeito à questão salarial, visto que Dória efetuou um comentário indireto aos inspetores ao abordar a fixação provisória dos ordenados do corpo docente realizada em 1838. Ele anotou que os docentes das cadeiras de Latim, Grego, Aritmética e Geografia teriam 
direito a $500 \$ 000$ e os das cadeiras de Desenho e Música, a 400\$000, acrescentando que "enquanto desse lição única semanal o professor de Francês receberia $200 \$ 000$, tanto quanto os inspetores e caso estes pelo seu preparo servissem de substituto se lhes abonaria mais 100\$000." (DÓRIA, 1997, p. 36). A passagem pontuou não apenas a remuneração percebida pelos inspetores (duzentos mil réis), como também a possibilidade de servirem como professores substitutos. Mais adiante, quando estava tratando dos acontecimentos entre os anos de 1844 e 1851, Dória confirmou essa possibilidade ao citar o nome do inspetor José da Silva Pinheiro Freire e inteirar que tinha atuado como professor substituto interino de Português e Latim na reitoria de Antônio de Arrábida (1771-1850), bispo de Anemúria e primeiro reitor do CPII (1837-1839).

Outro tópico reportou-se à conduta deles. Nos dois casos em que constatei isso os inspetores não foram o objeto central, figurando de modo genérico. Em um momento no qual Dória discorreu sobre um ofício enviado em 1838 pelo bispo-reitor, fez questão de aludir à parte em que o bispo de Anemúria valorizou determinados trabalhadores da escola num contexto de dificuldades devido ao número diminuto dos serventes: "eu não sei o que sucederia se esses zelosos empregados, inclusive os inspetores de alunos, e o Capelão não se dedicassem com toda boa vontade e com grande zelo a todo serviço, até braçal e grosseiro." (DÓRIA, 1997, p. 35). Já ao levantar o histórico do ilustre ex-aluno Álvares de Azevedo (1831-1852), Escragnolle Dória lembrou sua prática de fazer caricatura dos inspetores, justificando ser comum o fato de que "[...] inspetores e alunos nem sempre se entrestimam (sic)." (DÓRIA, 1997, p. 63). Conquanto naturalizasse as tensões entre estes sujeitos, observou haver harmonia no CPII, afirmando: "Os inspetores, à parte relações e quizílias com certos alunos, eram pessoas estimáveis, aturando muito." (DÓRIA, 1997, p. 64). Destes dizeres desvela-se um paradoxo: se inspetores eram tão zelosos e estimáveis, por que Dória quase não lembrou seus nomes?

0 terceiro tipo de menção aos inspetores relacionou-se a sua nomeação na escola. Nestes casos, o autor da MHCPII foi um pouco mais específico. Ele informou o requerimento de José Ferraz de Oliveira Dourado ${ }^{13}$ para ocupar o cargo no final de 1838 e o aval do vice-reitor concedendo-lhe uma nomeação interina. Da mesma maneira, para participar que dentre os integrantes do corpo de inspetores de 1851 constava Felippe Hypollito Ache, o qual posteriormente se tornou lente da Escola de Marinha, comentou: "Estendia-se o escrúpulo nas nomeações até o corpo de inspetores, buscando o Governo não fossem somente manequins para manutenção de disciplinas, sim homens de certa ou boa capacidade mental e até pedagógica." (DÓRIA, 1997, p. 72). Por fim, sublinho um relato de 1845 no que tange à negação da nomeação efetiva de um inspetor cujo nome não disse, qualificando-o somente como alguém que viera do Convento do Carmo. Abordando as providências do governo em relação ao colégio, escreveu:

Por outro lado, tendo conhecimento da nomeação, embora a título interino, de um inspetor dos internos do Colégio, o Governo cientificara ao reitor não confirmar tal nomeação. E por quê? Fora o Ministro Almeida Torres informado de haver sido o mesmo inspetor despedido do noviciado do Convento do Carmo da Corte, por irregularidade de comportamento. Declarava o Governo ao reitor que 'não podendo ser confirmada a nomeação, fazia-se por isso desnecessário continuar o inspetor a servir cargo interino para se conhecer da sua capacidade e morigeração'"' (DÓRIA, 1997, p. 60).

De acordo com um ofício de 24/07/1845 do reitor Joaquim Caetano da Silva (1810-1873) - que administrou a escola entre 1839 e 1851 -, tratava-se de Flaminio Antonio Natividade Coutinho, o qual, conforme outro ofício do mesmo mês, partiu da escola após 22 dias de serviço (BRASIL, 2019). 0 nome e o tempo de serviço de Coutinho, todavia, não foram as

13 Em um ofício e em dois recibos de pagamento figurou o nome José Ferraz de Oliveira Durão (BRASIL, 2019). 
únicas informações sobre os inspetores que Dória deixou escapar.

\section{Os inspetores de alunos em outras fontes}

No decorrer dos 20 anos do intervalo considerado (1837-1857), foram publicados diversos decretos e regulamentos que modificaram a organização da instrução pública de modo geral, ou estritamente o CPII. ${ }^{14}$ Dois deles são úteis quando se abordam os inspetores de alunos. Conforme o documento que fundou a instituição (BRASIL, 1837), professores, substitutos e inspetores de alunos seriam os empregados para cuidar do ensino, direção e vigia na escola. 0 regulamento expedido no mês subsequente (BRASIL, 1838) apresentou outros pontos convergentes entre as competências deles. Tanto professores quanto inspetores deveriam entregar ao vice-reitor aos sábados à noite "um mapa sobre o procedimento, e trabalho dos Alunos" (BRASIL, 1838) - art. 13 e $23 .{ }^{15} \mathrm{~A}$ ambos seria facultada a imposição aos alunos dos castigos de suspensão parcial ou total do recreio, e privação de passeio com trabalho extraordinário. Ademais, os substitutos que não estivessem exercendo o magistério serviriam de inspetores e, em caso de necessidade, os inspetores com as necessárias habilitações atuariam como substitutos. E os ocupantes dos três cargos poderiam reger aulas nas férias com o recebimento de uma gratificação proposta pelo reitor.

Havia, contudo, direitos e deveres privativos dos inspetores. Diferentemente dos professores que, caso quisessem comer no estabelecimento de ensino, deveriam ceder parte de seus ordenados para este fim, inspetores seriam alimentados gratuitamente às custas

14 Eles se encontram no formato impresso, estando também disponíveis nos sites da Câmara dos Deputados e do Senado Federal.

15 Ao transcrever fontes primárias neste texto, respeitei a pontuação e a gramática originais, mas atualizei a ortografia das palavras. do colégio. ${ }^{16}$ Afinal, eles deveriam fazer suas refeições junto aos alunos e morar na escola, mantendo comunicação entre seus aposentos e os dos meninos para vigiar sua entrada e saída. Na verdade, a lei previa que eles somente poderiam se deitar após conferir que todos os estudantes estivessem dormindo. $\mathrm{E}$ cada inspetor se responsabilizaria por dirigir uma classe entre 30 e 35 meninos nas quais os alunos seriam repartidos, e escrever relatórios diários sobre a mesma. Além disso, fazia parte das atribuições tomar a lição dos alunos, examinar os livros que possuíssem e acompanhá-los a passeio. Em suma, consoante o legislador, no art. 25 da Lei, "devem eles ter sempre em vista que de sua vigilância, e firmeza, assim como de sua moderação depende essencialmente a boa educação dos Alunos" (BRASIL, 1838).

Esses dispositivos legais foram proveitosos para delinear a dimensão da atuação dos inspetores de alunos dentro do CPII, já revelando um contraste com a narração hesitante de Dória. Entretanto, o material trocado entre os reitores da escola e os ministros da Secretaria de Negócios do Império propiciou uma aproximação mais razoável da prática da instituição. ${ }^{17}$ 0 exame dos maços de manuscritos contendo ofícios, relatórios, requerimentos, despachos, folhas e recibos de pagamento forneceu o encontro de informações sobre 65 inspetores de alunos do período em questão. Algumas delas foram confirmadas pelo Almanak Laemmert (LAEMMERT; LAEMMERT, 2020), ${ }^{18}$ que é de grande utilidade para obter nomes e endereços dos ocupantes de cargos de diversas instituições ao longo do Império. Todavia, no tocante ao assunto tratado neste artigo, seu uso foi limitado por restrições do próprio documento. Não apenas porque se iniciou no ano de 1844 - o que deixa descoberto o período de 1837 a

16 De acordo com o artigo 204, a gratuidade de alimentação estendia-se ao capelão (BRASIL, 1838).

17 Estes documentos estão disponíveis em meios físicos tanto no Arquivo Nacional (AN) quanto no Núcleo de Documentação do CPII (NUDOM).

18 Ele encontra-se no formato impresso na Biblioteca Nacional, estando também disponível em seu site. 
1843 -, como também devido ao silêncio na exposição sobre os inspetores de alunos do CPII, os quais não foram pontuados no documento entre 1846 e 1858, esquecimento sobre o qual não se apresentou justificativa.

Um traço que pude perceber a partir da sistematização dos dados sobre esses inspetores, extraídos principalmente dos ofícios, foi sua origem, uma vez que tive acesso ao local de nascimento de mais da metade deles. Foram arrolados sete imigrantes, sendo cinco franceses, um polonês e um grego. Mesmo deduzindo que os 58 restantes fossem cidadãos brasileiros, disponho da confirmação de 36 homens, dos quais 14 tiveram sua província natal especificada. Eram cinco trabalhadores provenientes da Corte, três do Rio de Janeiro, e um de cada uma das seguintes províncias: Alagoas, Bahia, Espírito Santo, Minas Gerais, Santa Catarina e São Paulo. Esta diversidade testifica a capacidade do Município Neutro da Corte, a sede do Império, de atrair força de trabalho resultante de migrações internas e externas desde a primeira metade do século XIX.

Apesar do predomínio dos naturais do Brasil, localizei um discurso favorável àqueles que dominavam línguas estrangeiras. Em um ofício no qual explanou sua pretensão de contratar o francês Francisco Affonso Clairet em 1846, Joaquim Caetano da Silva argumentou: “[...] além de outros preciosos requisitos, possui o de conhecer e pronunciar perfeitamente a sua língua, e pode por isso ser de muita utilidade aos alunos" (BRASIL, 2019). Este reitor apresentou uma defesa similar em prol dos brasileiros Francisco José de Mello e João Peixoto Gutierres Palhinha, anunciando que eles sabiam francês e inglês. Constantino Castorchi, por seu turno, parecia reunir grandes atributos por conhecer o grego moderno e o antigo, o francês, o inglês e o italiano. E penso ser digno de nota o parecer do vice-reitor Leandro Rebello Peixoto e Castro - que à época exercia a reitoria interinamente depois da saída de Antônio de Arrábida - quanto à candidatura de José Ferraz de Oliveira Dourado em 1838:
Parece-me um moço de juízo; é bem instruído na gramática latina; teve estudos completos no Colégio de Jacuecanga na Ilha Grande, por isso a aritmética, a álgebra, a geometria, a língua francesa e a filosofia não lhe são desconhecidas, ainda que confesse estar nestas últimas faculdades algum tempo esquecidas, por ter sido aplicado por seu pai alguns anos à administração da sua roça. Pelo que me parece estar nas circunstâncias de poder ser aproveitado. (BRASIL, 2019).

Se é provável que tivesse existido certa expectativa quanto aos conhecimentos pedagógicos dos inspetores, principalmente em relação aos saberes linguísticos, não observei ressalvas quanto à idade. É bem verdade que, em 1846, Caetano da Silva retratou positivamente José Alves da Silva como um aspirante idôneo por ser pai de família, ter servido como tenente e dispor de 52 anos, enquanto na década de 1850 pareceu necessitar enfatizar que o recém-contratado Pedro José Vieira, de 22 anos, apresentava "maior desenvolvimento físico e moral do que mostra na idade" (BRASIL, 2019). Ainda assim, detectei terem trabalhado no CPII inspetores desde a faixa etária dos 20 até os 60 .

Outro aspecto que tive a chance de identificar com a leitura desses documentos foi a acumulação de funções de alguns inspetores dentro do colégio. Tertulliano José Grandão também foi sacristão e bedel. ${ }^{19}$ Ignacio Viegas Tourinho Rangel desempenhou igualmente o papel de escriturário da tesouraria. Seu presuntivo parente, Guilherme Thompson Viegas Tourinho Rangel, teve o encargo de bedel. ${ }^{20}$ José Picitello recebeu um adicional por inspetor da vestiaria. E Fernando de Oliveira Alzamora, Francisco Affonso Clairet, José Teixeira de Sousa e João Dias Ferraz da Luz perceberam

19 De acordo com recibos de pagamento, entre 29 de dezembro de 1838 e 31 de agosto de 1839, ele percebeu como sacristão; entre 30 de setembro de 1839 e 30 de novembro de 1840, como bedel; e apenas em 31 de dezembro de 1839 , como inspetor. Ou seja, quando se tornou bedel, provavelmente deixou de ser sacristão. E somente depois de já ter exercido as duas funções ocupou-se de inspetor, o que parece ter vigorado pouco tempo. Em 1840, acredito ter ele exercido somente o cargo de bedel (BRASIL, 2019).

20 De acordo com os recibos de pagamento, ele provavelmente iniciou na escola como bedel (1842-1866), tornando-se inspetor a partir de 1860. (BRASIL, 2019) 
gratificações por atuarem como inspetores da enfermaria, tendo este último sido ainda porteiro e substituto de Aritmética. ${ }^{21}$

De todos os progressos na compreensão das dinâmicas laborais em relação aos inspetores de alunos, acredito que o mais proeminente corresponda aos motivos de retirada do CPII. Houve alguns casos em que deduzi ter ocorrido demissão por interesse da escola, apesar de repetidamente o reitor Caetano da Silva não manifestar muita clareza quanto às razões de saída de vários trabalhadores. Em 12 de novembro de 1842 ele informou que Antonio Luiz Torres de Aguiar foi suspenso por "ato escandaloso" (BRASIL, 2019). Depois disso não apareceram mais pistas de sua presença na escola. Três anos depois, classificou Justino Pires Garcia como "muito bem morigerado" mas "minimamente frouxo" (BRASIL, 2019). Em 22/02/1847 vagamente afirmou que Constantino Castorchi "não convinha conservado" (BRASIL, 2019). Logo ele, um rapaz de 32 anos... E no ano de 1849 relatou o seguinte sobre Joaquim José Fernandes da Silva: "Parece-me que este inspetor desempenha este ano as suas obrigações muito bem; mas estou persuadido que, por culpas antigas, perdeu para sempre a força moral; e tenho-o por homem de mau coração, capaz de uma perseguição sistemática." (BRASIL, 2019).

Em outras situações, contudo, as causas ficaram mais patentes. Em 29 de agosto de 1838, o bispo de Anemúria solicitou orientações de como proceder num caso de animosidade entre os inspetores José da Silva Pinheiro Freire e Innocencio Vellozo Pederneira, ambos na escola desde a abertura das aulas. Freire teria acusado Pederneira de ter cometido "crime péssimo", o que levou a classe dos pequenos a conjurarem-se (BRASIL, 2019). A despeito de não ter

21 Iniciou na escola como inspetor de alunos em abril de 1838. Em 12 de novembro de 1838 enviou um requerimento solicitando uma gratificação pelo cuidado da enfermagem. Há um recibo de pagamento com data de 30 de novembro de 1838 , em que recebeu cinquenta mil réis pela função de porteiro. Em janeiro de 1839 ministrou a cadeira de Aritmética como substituto nas lições de férias. Deixou a escola em janeiro de 1840 (BRASIL, 2019). encontrado uma resposta dos representantes da pasta da instrução pública, inferi a saída dos dois em razão de não ter identificado outros vestígios sobre eles. Já na época de Caetano da Silva, contou-se sobre Paulo José Gomes Marques e Cunha: "[...] não obstante haver ele procedido muito satisfatoriamente nestes 18 dias, porque hoje mesmo fui informado de que do Colégio de Nova Friburgo, em que era professor, fora ele despedido por ser sodomita." (BRASIL, 2019). Como nos outros casos, após este relato não observei outros dados sobre este trabalhador no CPII.

Em contrapartida, deparei com uma evidência singular de demissão a pedido em um requerimento enviado diretamente aos representantes do Império, que é marcado pelas estratégias discursivas dos suplicantes daquele tempo.

Diz Manoel Maximianno Pereira Pinto, Inspetor de Alunos do Imperial Colégio de Pedro $2^{\circ}$ nomeado por Decreto de 1을 Junho do corrente ano de 1839, que tornando-se absolutamente incompatível com os estudos, o que se aplica o exercício de Inspetor de Alunos, pois pretende seguir a carreira literária, e precisa aplicar-se ao conhecimento de seus deveres: por isso com todo o respeito súplica a V.M.I. [Vossa Majestade Imperial] lhe conceda a demissão de Inspetor, de que ao presente se acha encarregado. (BRASIL, 2019).

Ainda que não tenha descoberto outros indícios tão explícitos, suponho ter havido mais dispensas por iniciativa dos próprios trabalhadores que da administração da escola. 0 que insinuou esta hipótese foi a percepção do abreviado tempo de permanência dos inspetores de alunos no CPII. Tendo estipulado a duração do serviço de 57 deles, pude constatar que $72 \%$ ficaram menos de um ano trabalhando no estabelecimento, identificando, inclusive, dois inspetores que lá estiveram somente por um dia. Aliás, de acordo com as informações que encontrei, exerceram a função por no mínimo cinco anos somente Ignacio Viegas Tourinho Rangel (1839-1844), Fernando de Oliveira Alzamora (1839-1845), Guilherme Thompson 
Viegas Tourinho Rangel (1842-1869) e Luiz José de Carvalho (1850-1870), sendo considerável o fato de os dois últimos terem deixado a escola, respectivamente, apenas em virtude de aposentadoria e falecimento.

É possível que outros indivíduos tenham apresentado alegações parecidas com a de Manoel Pinto, dissimulando problemas de outra natureza com a máscara do discurso da vocação, mas não foi achado ofício, portaria ou requerimento neste sentido. Considerando a complexidade da realidade social, marcada por monopólios, desigualdades e incessantes conflitos, a explicação mais plausível para esse intenso fluxo de pessoas no cargo relaciona-se às necessidades da vida material. 0 conteúdo de um ofício de Joaquim Caetano da Silva do final de 1849 proporcionou esta suspeita.

Parecendo-me de interesse vital para este colégio, que se empregue alguns meios eficazes para atrair e conservar bons inspetores de alunos internos e externos, e também um bom bedel das aulas, porque o bedel, além de ser substituto nato do inspetor de alunos externos, tem o encargo melindrosíssimo de apontar as faltas dos professores e dos alunos: tenho a honra de propor a V. Ex. a as seguintes providências, em que muito confio.

Quanto aos inspetores de alunos internos: que cada um deles no fim do primeiro ano de serviço, além do ordenado fixo de 400 mil réis, 50.000 réis de gratificação; no fim do segundo ano, 100.000 réis; no fim do terceiro ano 150.000 réis; e assim anualmente mais cinquenta mil réis sobre a gratificação do ano anterior.

Quanto aos inspetores de alunos externos e o bedel das aulas: que cada um deles receba no fim do primeiro ano de serviço, além do vencimento fixo de 240.000 réis, vinte e cinco mil de gratificação; no fim do segundo ano cinquenta mil réis; no fim do terceiro ano setenta e cinco mil réis; e assim anualmente vinte e cinco mil réis sobre a gratificação do ano anterior. (BRASIL, 2019).

No fragmento houve uma interessante descrição de uma das atribuições do bedel, cargo que só foi previsto na legislação aproximadamente dez anos mais tarde (BRASIL, 1857). 0 texto também indicou a separação dos inspeto- res nas categorias de responsáveis por alunos internos e externos - algo que não figurou no extenso regulamento de 1838 -, demonstrando, ainda, a concepção de que aqueles que eram compelidos a dormir no estabelecimento para vigiar os dormitórios dos estudantes faziam jus a uma maior vantagem pecuniária. No entanto, a ideia crucial recomendada pelo segundo reitor do CPII foi a proposta de remuneração progressiva em uma tentativa de fidelizar trabalhadores no cargo.

Ainda que o conselho tenha parecido coerente à primeira vista, devo informar que, conforme alguns ofícios, recibos e folhas de pagamento, desde 1846 existiam alguns inspetores de alunos internos que já recebiam mais que o valor demandado na solicitação (BRASIL, 2019). Sem embargo, sinalizo que nesta época não pareceu haver um padrão remuneratório para a categoria. Aludindo aos dois inspetores brasileiros já referidos por sua habilidade de falar inglês e francês, é possível vislumbrar a falta de uniformidade. Enquanto Francisco José de Mello ingressou na escola em 15 de junho de 1847 com o vencimento de quatrocentos mil réis anuais, João Peixoto Gutierres Palhinha iniciou seu exercício no dia 01 de janeiro de 1847 , tendo o ordenado fixado em seiscentos mil réis anuais. 0 embaraço se agrava quando se compara com a condição de outros inspetores, como é o caso de Luiz de Araújo Rangel, que começou dia 22 de julho de 1847, recebendo somente trezentos mil réis anuais. Talvez a insatisfação com a prática da escola de distinguir financeiramente sujeitos que possuíam as mesmas atribuições tenha sido o motivo para ele ter permanecido no CPII menos de quatro meses (BRASIL, 2019).

Em que pese sua tentativa de simular essas discrepâncias, a sugestão de Caetano da Silva possui o mérito de estimular alguma normatização e o arranjo de uma espécie de plano de carreira. Todavia, esse plano não deve ter sido acatado pelo governo imperial porque a pauta foi matéria de um ofício do reitor Manoel Pacheco da Silva (1812-1889), que atuou na 
escola entre 1856 e 1872, sendo seu último administrador antes da divisão em dois estabelecimentos distintos. ${ }^{22}$ Logo no início de sua reitoria, fez a solicitação:

Tendo-se despedido deste colégio dois inspetores, por terem encontrado fora empregos mais vantajosos, e estando também outro com os mesmos planos, como me consta; peço a V. Ex. a autorização para dar aos que ficam, e que são felizmente os mais zelosos, uma gratificação ao menos de doze mil réis mensais pelo aumento do serviço até que apareça pessoa com as qualidades requeridas tão difícil, quão pesado encargo. (BRASIL, 2019).

Novamente colocou-se na ordem do dia a urgência em tomar medidas para evitar a rotatividade dos inspetores de alunos repetindo-se a estratégia de conceder gratificação pelo tempo de serviço. Infelizmente há um hiato quanto aos dados sobre a retribuição dos inspetores de alunos entre 1852 e 1857 e não foi possível confirmar a aplicação da reivindicação de Pacheco da Silva. Todavia, um ofício escrito em 1874 pelo reitor do Externato José Joaquim da Fonseca Lima (1815-1882), que esteve no cargo entre 1873 e 1880 , evidenciou a continuidade das controvérsias.

Havendo sido elevados pelo Aviso de 7 do corrente os vencimentos dos Inspetores de Alunos deste Externato, tenho a honra de consultar a V. Ex. - se devem participar desse os Inspetores contratados em virtude do Aviso de 14 de janeiro deste ano, bem como os interinos por mim nomeados nos termos da última parte do artigo 76 do Regulamento anexo ao Decreto 2006 de $24 / 10 / 1857$, e no caso afirmativo rogo a V. Ex. ${ }^{a}$ que se digne de expedir suas ordens a fim de que no Tesouro Nacional se efetue o pagamento de conformidade com a folha que mensalmente lhe houver de ser presente de minha parte. (BRASIL, 2019).

A indagação de Fonseca Lima deixou transparecer não apenas que a insuficiência remuneratória se manteve constantemente, acarretando contínuos requerimentos de elevação dos ordenados, como também que

22 Ele foi o quarto reitor geral (1852-1857) e o primeiro reitor do Externato (1858 e 1872). se deu prosseguimento à prática de pagar os inspetores de modo desproporcional. Aqui, ao menos se demonstrou existirem critérios mais plausíveis para a remuneração assimétrica, como o fato de alguns inspetores serem interinos e ainda não terem sido confirmados no cargo por estarem em fase de experiência.

Essas posturas contraditórias, contudo, não devem parecer uma particularidade do CPII. Desde o movimento de derrubada do "muro de Berlim historiográfico" (CHALHOUB; SILVA, 2010, p. 15) entre as histórias das senzalas e das fábricas, isto é, entre os estudos da escravidão e do movimento operário, alguns autores têm alcançado entendimentos profícuos sobre o século XIX. O principal deles é a conclusão de que as relações laborais de trabalhadores livres e escravizados compartilhavam certas dinâmicas e estruturas comuns. Consoante Marcelo Mattos (2008, p. 46), “[...] enquanto o peso da escravidão urbana foi elevado, a variação salarial dos trabalhadores livres não se pautava apenas pelos critérios clássicos de oferta e procura de mão-de-obra proletarizada". De acordo com sua interpretação, diversas condicionantes que refletiam as hierarquias sociais e raciais indubitavelmente afetavam a fixação dos salários dos trabalhadores livres. E Robério Souza (2015, p. 172) corrobora esta visão, explicando que numa sociedade escravista o "[...] que se pretendia em relação à maioria das pessoas pobres, independentemente de sua condição jurídica" era forçá-las para o trabalho. Em outras palavras, em tempos de escravismos, a realidade era a precariedade das condições laborais.

\section{Conclusão}

Neste artigo pretendi tanto explorar um eixo temático que praticamente não é levado em conta na historiografia do CPII, quanto questionar a MHCPII como uma fonte imprescindível para o estudo do colégio, apresentando algumas de suas questões e limites. Ao analisar o texto de Escragnolle Dória procurei 
demonstrar que os inspetores de alunos não receberam a devida atenção, tendo sido retratados de maneira bastante viciada. Acredito que isso deva ter ficado visível quando examinei outras fontes, como as leis, o Almanak Laemmert (LAEMMERT; LAEMMERT, 2020), e os diversos manuscritos frutos da comunicação entre a reitoria da instituição e a seção da burocracia imperial encarregada da instrução pública. Afinal, ao comentar os dados delas extraídas, tentei provar que o "resumo do essencial" feito pelo professor esqueceu de incluir uma série de informações sobre os inspetores, tais quais elementos biográficos, como nome, origem e idade, e elementos socioeconômicos, como suas condições de trabalho. Assim procedendo, o memorialista não incluiu em seu exemplar um importante aspecto da história do estabelecimento em seus primeiros anos de funcionamento que, na verdade, não configurava uma especificidade do CPII, mas uma consequência das relações escravistas: a precariedade da situação dos trabalhadores. Por não ter abarcado tensões como esta, que são resultantes de uma realidade social complexa e desigual, penso que sua obra perpetua hierarquias sociais e raciais.

A questão é que, por reconhecer “[...] que as ideias não passeiam nuas pela rua; que elas são levadas por homens que pertencem eles próprios a conjuntos sociais" (SIRINELLI, 1996, p. 257-258), para além de julgar os problemas que aparecem no texto de Dória como dilemas meramente individuais, conjecturo ser mais produtivo conceber que esse modo de representar esses sujeitos foi socialmente produzido, inserindo-se no cenário mais abrangente das circunstâncias socioeconômicas, políticas e culturais do tempo e do espaço em que escreveu. Tomando a expressão emprestada de Márcia Motta (1998, p. 81), é preciso refletir na amnésia social produzida oficialmente e, "[...] quando falamos de amnésia, devemos estar atentos às conjunturas históricas, que explicam a maneira pela qual se operou o esquecimento de determinado acontecimento". Daí a pertinência de interrogações como estas: A quem interessou/ interessa que os conflitos no interior de uma escola fundada no século XIX fossem/sejam omitidas? Por quê? E até quando essas deslembranças serão promovidas?

\section{REFERÊNCIAS}

ANDRADE, V. Colégio Pedro II: um lugar de memória. 1999. Tese (Doutorado em História) Universidade Federal do Rio de Janeiro (UFRJ), Rio de Janeiro, 1999.

ALVES, R. José Verissimo Dias de Mattos: um crítico na direção do Gymnasio Nacional (18921898). 2006. Dissertação (Mestrado em Educação) - Universidade Federal Fluminense (UFF), Niterói, RJ, 2006.

BRASIL. Câmara dos Deputados. Decreto s/n, de 02 de dezembro de 1837. Convertendo o Seminário de São Joaquim em colégio de instrução secundária, com a denominação de Colégio de Pedro II, e outras disposições. Rio de Janeiro, 1837. Disponível em: https://www2.camara.leg.br/ legin/fed/decret_sn/1824-1899/decreto-369792-dezembro-1837-562344-publicacaooriginal86295-pe.html. Acesso em: 25 mar. 2020.

BRASIL. Câmara dos Deputados. Regulamento no 8, de 31 de janeiro de 1838. Contém os estatutos do Colégio de Pedro Segundo. Rio de Janeiro, 1838. Disponível em: http://legis.senado.leg.br/ norma/561182/publicacao/15635716. Acesso em: 25 mar. 2020.

BRASIL. Câmara dos Deputados. Decreto no 2006, de 24 de outubro de 1857. Aprova o regulamento para os colégios públicos de instrução secundária do Município da Corte. Rio de Janeiro, 1857. Disponível em: https://www2.camara.leg.br/ legin/fed/decret_sn/1824-1899/decreto-369792-dezembro-1837-562344-publicacaooriginal86295-pe.html. Acesso em: 25 mar. 2020.

BRASIL. Arquivo Nacional. RIO 94. Fundo Educação. Série Ensino Secundário. Maços IE 4 26-35 e 42. Rio de Janeiro, 2019.

CHALHOUB, Sidney; SILVA, Fernando. Sujeitos no imaginário acadêmico: escravos e trabalhadores na historiografia brasileira desde os anos 1980 . Cadernos AEL, Campinas, SP, v. 14, n. 26, p. 12-45, 2010. Disponível em: https://www.ifch.unicamp. br/ojs/index.php/ael/article/view/2558. Acesso em: 14 abr. 2020. 
COLÉGIO PEDRO II. O Colégio Pedro II Contribuição Histórica aos 175 anos de sua fundação. Rio de Janeiro, 2013.

COLÉGIO PEDRO II. Memória Histórica do Colégio Pedro II. 180 anos de História na Educação do Brasil. Rio de Janeiro: Triunfal, 2018.

COLÉGIO PEDRO II. Comissão de Atualização da Memória Histórica do CPII. Rio de Janeiro, 2014. Disponível em: http://www.cp2. g12.br/using-joomla/extensions/components / content-component/article-categories/1493comiss\%C3\%A3o-de-atualiza\%C3\%A7\%C3\%A3oda-mem\%C3\%B3ria-hist\%C3\%B3rica-do-cpii. html. Acesso em: 10 abr. 2020.

CUNHA JÚNIOR, C. O Imperial Collegio de Pedro II e o ensino da boa sociedade brasileira. Rio de Janeiro: Apicuri, 2008.

DASSIE, B.; SOARES, F.; Eugenio de Barros Raja Gabaglia: vida e obra de um professor de Matemática. In: COLÓQUIO DE HISTÓRIA E TECNOLOGIA NO ENSINO DE MATEMÁTICA, 5., 2010, Recife. Anais [...]. Recife: Universidade Federal de Pernambuco, 2010. p. 1-5.

DÓRIA, Escragnolle. Memória histórica do Colégio de Pedro Segundo: 1837-1937. Brasília, DF: Instituto Nacional de Estudos e Pesquisas Educacionais Anísio Teixeira, 1997.

FERREIRA, M. A história da disciplina escolar ciências no Colégio Pedro II (1960-1980). 2005. 212 f. Tese (Doutorado em Educação) - Faculdade de educação, Universidade Federal do Rio de Janeiro (UFRJ), Rio de Janeiro, 2005.

FINOCCHIO, J. A inserção da Educação Física/ Gymnastica na escola moderna - Imperial Collegio de Pedro II (1837-1889). 2013. 258 f. Tese (Doutorado em Educação) - Programa de PósGraduação em Educação, Universidade Federal do Mato Grosso do Sul (UFMS), Campo Grande, 2013.

GASPARELLO, A. Construtores de identidades: os compêndios de História do Brasil no Colégio Pedro II (1838-1920). 2002. Tese (Doutorado em Educação) - Pontifícia Universidade Católica de São Paulo (PUC-SP), São Paulo, 2002.

HAUER, L. Colégio Pedro II no período da ditadura militar: subordinação e resistência. 2007.169f. Dissertação (Mestrado em Educação) - Faculdade de Educação, Universidade Federal Fluminense (UFF), Niterói, RJ, 2007.

HOBSBAWM, E. Sobre história. São Paulo:
Companhia das Letras, 1998.

JORNADA, J. Uma perspectiva histórica do Ensino de Química no Colégio Pedro II (1837- 1889). 2013. 97 f. Dissertação (Mestrado em Ciência, Tecnologia e Educação) - Centro Federal de Educação Tecnológica Celso Suckow da Fonseca (CEFET/RJ), Rio de Janeiro, 2013.

LAEMMERT, E.; LAEMMERT, H. Almanak administrativo, mercantil e industrial do Rio de Janeiro (Almanak Laemmert). Rio de Janeiro. Disponível em: http://objdigital.bn.br/acervo_digital/div_ periodicos/almanak/almanak.htm. Acesso em: 25 mar. 2020.

MARQUES, G. A educação do corpo e o protagonismo discente no Colégio Pedro II: mediações entre o ideário republicano e a memória histórica da instituição (1889-1937). 2011. 176 f. Dissertação (Mestrado em Educação) - Universidade Federal do Rio de Janeiro (UFRJ), Rio de Janeiro, 2011.

MASSUNAGA, M. o Colégio Pedro II e o ensino secundário brasileiro: 1930-1961.1989. Dissertação (Mestrado em Educação) - Universidade Federal do Rio de Janeiro (UFRJ), Rio de Janeiro, 1989.

MATTOS, M. Escravizados e livres. Experiências comuns na formação da classe trabalhadora carioca. Rio de Janeiro: Bom Texto, 2008.

MOTTA, M. História e memórias. In: MATTOS, M. (org.). História: pensar e fazer. Rio de Janeiro: Laboratório Dimensões da História, 1998. p. 73-89.

MOISES, A. Colégio Pedro II: controvérsias acerca de sua fundação. 2007.173 f. Dissertação (Mestrado em educação) - Universidade Estadual de Maringá (UEM), Maringá, PR, 2007.

NEVES, L. Colégio Pedro II. In: VAINFAS, Ronaldo (org.). Dicionário do Brasil Imperial (18221889). Rio de Janeiro: Objetiva, 2008. p. 147-148.

NUNES, S. Colégio Pedro II: a gênese de uma representação de escola excelente. 2007. $165 \mathrm{f}$. Dissertação (Mestrado em Educação) - Universidade Estácio de Sá (UNESA), Rio de Janeiro, 2007.

PENNA, F. Sob o nome a capa do imperador: a criação do Colégio de Pedro Segundo e a construção do seu currículo. 2008. Dissertação (Mestrado em Educação) - Faculdade de Educação, Universidade Federal do Rio de Janeiro (UFRJ), Rio de Janeiro, 2008.

PENNA, F. O "currículo colegial" do Colégio Pedro II. In: CHAVES, M.; LOPES, S. (org.). Instituições educacionais da cidade do Rio de Janeiro: um 
século de história (1850-1950). Rio de Janeiro: Mauad X/Faperj, 2009. p. 37-56.

POLON, T. Políticas Públicas para o Ensino Médio nos anos 90: trajetória do Colégio Pedro II/ RJ. 2004. Dissertação (Mestrado em Educação) Pontifícia Universidade Católica do Rio de Janeiro (PUC/RJ), Rio de Janeiro, 2004.

PATROCLO, L. B. A fundação do Colégio de Pedro II nas páginas da imprensa carioca do século XIX: os jornais A Aurora Fluminense e $O$ Chronista. In: CONGRESO IBEROAMERICANO DE HISTORIA DE LA EDUCACIÓN (CIHELA), 11., 2014, Toluca, México. Anais [...]. Toluca, México: Sociedad Mexicana de Historia de La Educación, 2014. p. 889-901.

RAZZINI, M. 0 espelho da nação: a antologia nacional e o ensino de português e de literatura (1838-1971). 2000. Tese (Doutorado em Letras) Universidade Estadual de Campinas (UNICAMP), Campinas, SP, 2000.

ROCHA, G. A trajetória da disciplina geografia no currículo escolar brasileiro (1837-1942). 1996. Dissertação (Mestrado em Educação) - Pontifícia Universidade Católica de São Paulo (PUC-SP), São Paulo, 1996.

ROCHA, G. O Colégio Pedro II e a institucionalização da Geografia escolar no Brasil Império. Giramundo, Rio de Janeiro, v. 1, n. 1, p. 15-34, jan./jun. 2014.

SANTOS, B. 0 currículo da disciplina escolar história no Colégio Pedro II - a década de 70 - entre a tradição acadêmica e a tradição pedagógica: a história e os estudos sociais. Rio de Janeiro: Mauad
X/FAPERJ, 2011.

SIRINELLI, J-F. Os intelectuais. In: RÉMOND, R. (org.) Por uma história política. Rio de Janeiro: Editora UFRJ, 1996. p. 231-269.

SOARES, J. 0 ensino de sociologia no Colégio Pedro II (1925-1941). 2009. Dissertação (Mestrado em Educação) - Universidade Federal do Rio de Janeiro (UFRJ), Rio de Janeiro, 2009.

SOUZA, Carlos. A educação como prática política: formação e renovação de repertórios pedagógicos do Segundo Reinado (o Colégio Pedro II, o Ginásio Baiano e o Culto à Ciência). 2015. Tese (Doutorado em Sociologia) - Universidade de São Paulo (USP), São Paulo, 2015.

SOUZA, Carlos. Ensinando a ser brasileiro: o Colégio Pedro II e a formação dos cidadãos na Corte Imperial (1837-1861). 2010. Dissertação (Mestrado em História Social da Cultura) Pontifícia Universidade Católica do Rio de Janeiro (PUC-RJ), Rio de Janeiro, 2010.

SOUZA, Robério. Trabalhadores dos trilhos. Campinas, SP: Ed. da UNICAMP, 2015.

TAVARES, J. A congregação do Colégio Pedro II e os debates sobre o ensino de matemática. 2002. Dissertação (Mestrado em Educação Matemática) - Pontifícia Universidade Católica de São Paulo (PUC-SP), São Paulo, 2002.

Recebido em: $15 / 04 / 2020$ Aprovado em: 28/08/2020 